\title{
Effects of Mixing Canola and Palm Oils with Sunflower Oil on the Formation of Trans Fatty Acids during Frying
}

\author{
Radwan S. Farag', Magdy A. S. El-Agaimy ${ }^{2}$, Bothaina S. Abd El Hakeem ${ }^{3}$ \\ ${ }^{1}$ Department of Biochemistry, Faculty of Agriculture, Cairo University, Giza, Egypt; ${ }^{2}$ Department of Fats \& Oils, Food Technology \\ Research Institute, Agriculture Research Centre, Giza, Egypt; ${ }^{3}$ Special Food and Nutrition Department, Food Technology Research \\ Institute, Agriculture Research Centre, Giza, Egypt. \\ Email: \{bothaina_2007,radwanfarag\}@yahoo.com
}

Received June $7^{\text {th }}, 2010$; revised July $5^{\text {th }}, 2010$; accepted July $8^{\text {th }}, 2010$.

\begin{abstract}
GLC analysis was conducted to indicate the formation of trans- C18 fatty acids of sunflower, canola and palm oils during frying. Blends of sunflower oil and palm oil or canola oil were obtained by mixing sunflower oil with palm or canola oils at the volume ratios of 60: 40, 40: 60 and $20: 80(\mathrm{v} / \mathrm{v})$, then heated at $180^{\circ} \mathrm{C} \pm 5^{\circ} \mathrm{C}$ for $5,10,15$ and $20 \mathrm{~h}$ in the atmospheric oxygen. GLC results demonstrate that the formation of trans C18-fatty acids was generally dependent upon the frying time and oil mixing ratios. Furthermore, mixing sunflower oil with oils rich in monounsaturated fatty acids (palm or canola oils) lowered the formation of trans-C18 fatty acids during frying.
\end{abstract}

Keywords: Sunflower Oil, Canola Oil, Palm Oil, Trans Fatty Acids, Frying Process, GLC Analysis

\section{Introduction}

Trans fats or trans fatty acids are unsaturated fatty acids with at least one double bond in the trans configuration. Trans fatty acids occur naturally in small amounts in foods produced from ruminant animals. However, most of trans fatty acids in the diet are produced during the process of partial hydrogenation of vegetable oils into semi-solid fats [1]. Also, trans-fatty acids can be formed from cis-unsaturated fatty acids by the effect of several bacteria, especially parasitic bacteria in the rumen of cattle which convert unsaturated lipids from cis to trans-isomers through a cis/trans isomerase [2].

Trans fatty acids have an adverse effect on blood lipids and have been shown to increase the risk of heart disease. Trans fatty acids increase LDL-cholesterol (the bad cholesterol) and decrease HDL-cholesterol (the good cholesterol) and overall, trans fatty acids increase LDL cholesterol (bad cholesterol) similarly to saturated fat, but, unlike saturated fat, they also decrease HDL cholesterol. As a result, the net effect of trans fat on the $\mathrm{LDL} / \mathrm{HDL}$ cholesterol ratio is approximately double that of saturated fat. It is worth noting that the risk of cardiovascular disease is increased if trans fatty acids are consumed in high amounts $[1,3]$. In addition, trans fatty acids appear to have an adverse effect on some lipoproteins and apoproteins when fed at relatively high levels [4]. In contrast, lower levels of trans fatty acids did not appear to be deleterious [5].
Deep-fat frying is one of the most processes used in all food preparations. Basically, this process includes immersing a food item in a large quantity of heated oil and reused several times before being disposed. Deep-fat frying produces a product with desired sensory characteristics, including fried food flavour, golden brown colour and a crisp texture [6]. This process has also been considered a source for the production of trans fatty acids. Formation of trans fatty acids during frying has been shown to be closely related to process temperature and time. In sunflower oil, the amount of trans isomers were found to be $1.10 \%$ when heated at $200^{\circ} \mathrm{C}$ for $40 \mathrm{~min}$ as compared to $11.45 \%$ at $300^{\circ} \mathrm{C}$ for the same duration of heating [7]. Conversely, Romero et al., [8] reported a very minimal production of eliadic acid in extra virgin olive oil, high oleic sunflower oil and sunflower oil. On the other hand, commercial frying and baking oils contain significant amount of trans fatty acids. In general, baked goods, fries snack foods (e.g., dough nuts, French fries) and fried fast-food items (e.g., fried chicken and fried fish) contain significant amounts of trans fatty acids [9].

It seems that cis/trans-isomerisation process depends on the most prominent fatty acids present in an oil. For instance, eliadic acid was the most abundant trans fatty acid in extra virgin olive oil fried potatoes while trans linoleic isomers were more abundant in sunflower oil. High oleic sunflower oil was in between [8]. 
In this context, the Food and Drug Administration (FDA) [10] ruled that the nutrition labels for all conventional foods and supplements must indicate the content of trans fatty acids. In addition, the Department of Agriculture made a limited intake of trans fatty acids a key recommendation of the new food-pyramid guideline subsequent to the recommendations of the Dietary Guidelines Advisory Committee [11] that the consumption of trans fatty acids be kept below $1 \%$ of total energy intake. Furthermore, the UK Faculty of Public Health and Royal Society for Public Health [12] proposed that consumption of trans fatty acids should be virtually eliminated.

A set of experiments was conducted in the present study where oils rich in monosaturated fatty acids (canola and palm oils) were mixed with sunflower oil at various volume ratios in an attempt to extent its shelf-life [13]. The major objective of the present work was to see if blending oils rich in monosaturated fatty acids with sunflower oil might lower the formation of trans fatty acid content of the binary oil blends during frying at $180^{\circ} \mathrm{C}$ for $5 \mathrm{~h}$ daily for 4 consecutive days.

\section{Materials and Methods}

\subsection{Oils}

1) Refined sunflower oil was obtained from Sila Edible Oil company (Kom Osheim, El-Fayoum governorate, Egypt). The oil peroxide and acid values were 1.2 (meq. active oxygen $\mathrm{Kg}^{-1}$ oil) and $0.08\left(\mathrm{mg} \mathrm{KOH} / \mathrm{g}^{-1}\right.$ oil), respectively.

2) Refined palm oil was obtained from Savola Sime company, 10th of Ramdan city , Sharkia governarate, Egypt . The oil peroxide and acid values were 0.14 (meq. active oxygen $\mathrm{Kg}^{-1}$ oil) and 0.043 (mg KOH g${ }^{-1}$ oil), respectively.

3) Canola seeds (Brassica species, Serwi 4 variety) were obtained from Oil Crops Department, Field Crops Research Institute, Agriculture Research Centre, Ministry of Agriculture, Giza, Egypt. The seeds were ground and packed in cheese cloth, pressed by hydraulic Carver (model 2759 S/N 2759-584 Freds. Carver Inc., U.S.A.). The produced oil was filtered through Whatman filter paper No.1 and kept in a brown glass bottle at $7^{\circ} \mathrm{C}$.

\subsection{Frying Process}

A known amount (2 L) of each of refined sunflower, palm and canola oils were separately placed in a Cordon Bleu deep fat-fryer (Model DZ-05D, China) equipped with a temperature controller. Portions of sunflower oil were mixed with palm oil or canola oil at ratios of 60: 40, 40:60 and 20: 80, $(\mathrm{v} / \mathrm{v})$. Potato chips $(2 \mathrm{~mm}$ thickness $\times$ $40 \mathrm{~mm}$ width $\times 50 \mathrm{~mm}$ length ) were soaked in a sodium chloride solution ( $10 \%, \mathrm{w} / \mathrm{v})$ for $0.5 \mathrm{~h}$ and fried in different oil samples at $180^{\circ} \mathrm{C} \pm 5^{\circ} \mathrm{C}$. The frying process was conducted 4 times each day and the frying period was $5 \mathrm{~h} \mathrm{day}^{-1}$. This process was repeated for 4 consecutive days. Oil samples were taken every $5 \mathrm{~h}$ and the total continuous heating period was $20 \mathrm{~h}$. The oil samples were left to cool down then stored at $-10^{\circ} \mathrm{C}$ for fatty acid analysis.

\subsection{Fatty Acid Compositions of Fried Sunflower, Palm and Canola Oils and Their Binary Mixtures}

Capillary gas chromatography (HP 6890) was used for the qualitative and quantitative determinations of fatty acids of the oil samples and reported in relative area percentages. Fatty acids were transesterified into their corresponding fatty acid methyl esters (FAMEs) by shaking a solution of oil (ca. $0.1 \mathrm{~g}$ ) in heptane $(2 \mathrm{ml})$ with a solution of methanolic potassium hydroxide $(0.2 \mathrm{ml}, 2 \mathrm{~N})$. The FAMEs were identified using a gas chromatograph equipped with DB-23 (50\%- cyano propyl)-methylpoly siloxane) capillary column $(60 \mathrm{~m} \times 0.32 \mathrm{~mm} \times 0.25 \mu \mathrm{m}$ film thickness) and a flame ionization detector. Nitrogen flow rate was $0.6 \mathrm{ml} / \mathrm{min}$, hydrogen and air-flow rates were 45 and, $450 \mathrm{ml} / \mathrm{min}$, respectively. The oven temperature was isothermally heated at $195^{\circ} \mathrm{C}$. The injector and the detector temperatures were $230^{\circ} \mathrm{C}$ and $250^{\circ} \mathrm{C}$, respectively. MEFAs were identified by comparing their retention times with known fatty acid standard mixture. Peak areas were automatically computed by an integrator. All GC measurements for each oil sample were made in triplicate and the average values were reported.

\section{Results and Discussion}

\subsection{Trans C18 Fatty Acids of Individual Oils}

In this set of experiments, the major concern is focused on the formation of trans-fatty acids (eliadization) during heating at $180^{\circ} \mathrm{C} \pm 5^{\circ} \mathrm{C}$ for various periods. It is worth mentioning that the fatty acid profile of fresh sunflower oil was discussed earlier in detail [13]. Table 1 shows the changes in heated sunflower oil during frying. No trans-oleic acid (elaidic) was found after the first $5 \mathrm{~h}$ heating period. Afterwards, its content was slightly and gradually increased towards the end of heating period $(20 \mathrm{~h})$. Similar results were noticed with trans linoleic acid (linoelaideic acid). It is worth mentioning that the amount of trans linoleic acid was much greater than that of trans-oleic acid (Figure 1). Similar findings were reported by Hunter and Applewhite [9] who reported that the trans amounts of fatty acids increased gradually by increasing the heating period.

Looking at trans fatty acid profile of heated palm oil at $180^{\circ} \mathrm{C} \pm 5^{\circ} \mathrm{C}$ for various periods, one can deduce the following remarks. The amount of trans-oleic acid was formed at $5 \mathrm{~h}$ and its amount become constant throughout the entire heating period $(20 \mathrm{~h})$. It is worth mentioning that the amount of trans-oleic acid was much lower than 
Table 1. Trans and their parent fatty acid compositions (area \%) of heated sunflower, palm and canola oils for various periods

\begin{tabular}{|c|c|c|c|c|c|c|c|c|}
\hline \multirow{2}{*}{ Oil blend } & \multicolumn{8}{|c|}{ Heating period (h) } \\
\hline & 5 & 10 & 15 & 20 & 5 & 10 & 15 & 20 \\
\hline & \multicolumn{4}{|c|}{$\underline{\text { Trans-oleic acid (elaidic) acid }}$} & \multicolumn{4}{|c|}{$\underline{\text { Cis-oleic acid }}$} \\
\hline Sunflower oil & ND & 0.03 & 0.13 & 0.15 & 29.16 & 28.33 & 29.13 & 29.22 \\
\hline Palm oil & 0.03 & 0.04 & 0.04 & 0.05 & 40.25 & 39.58 & 39.57 & 41.20 \\
\hline \multirow[t]{2}{*}{ Canola oil } & 0.03 & 0.06 & 0.11 & 0.14 & 46.25 & 46.71 & 47.15 & 49.14 \\
\hline & \multicolumn{4}{|c|}{$\underline{\text { Trans-linoleic (linolaidic) acid }}$} & \multicolumn{4}{|c|}{$\underline{\text { Cis-linoleic acid }}$} \\
\hline Sunflower oil & ND & 1.09 & 1.22 & 1.5 & 57.52 & 57.99 & 56.40 & 55.42 \\
\hline Palm oil & 0.08 & 0.08 & 0.08 & 0.09 & 12.09 & 10.20 & 9.40 & 9.31 \\
\hline Canola oil & 0.02 & 0.05 & 0.05 & 0.05 & 18.33 & 17.76 & 17.88 & 16.41 \\
\hline \multicolumn{9}{|c|}{ Total trans $\mathrm{C} 18$ fatty acids } \\
\hline Sunflower oil & ND & 1.12 & 1.35 & 1.65 & & & & \\
\hline Palm oil & 0.11 & 0.12 & 0.12 & 0.14 & & & & \\
\hline Canola oil & 0.14 & 0.11 & 0.16 & 0.19 & & & & \\
\hline
\end{tabular}

ND refers to non detected fatty acid

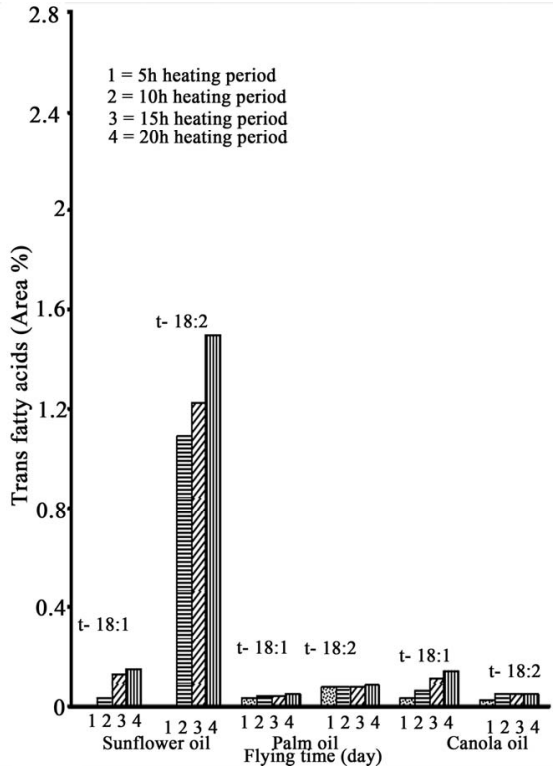

Figure 1. Trans fatty acids of sunflower, palm and canola oils heated for various periods. t- 18: 1 and t- 18: 2 acids refer to trans-oleic and trans-linoleic fatty acids, respectively

that found in sunflower oil. However, palm oil contains high level of oleic acid (parent acid) than that of sunflower oil. On the contrary, the level of linoleic acid in sunflower oil was much greater than that present in palm oil and the level of trans linoleic acid was about 16 times as great as that present in palm oil at the end heating period (20 h) (Table 1).

Dealing with canola oil, the amount of trans-oleic was found after heating for $5 \mathrm{~h}$ and gradually increased throughout at the entire heating period $(20 \mathrm{~h})$. The amount of trans-oleic acid at the end of the heating period was about the same as that of sunflower oil. The amount of trans oleic acid increased in the following order depending on the oil type: sunflower oil $>$ canola oil > palm oil. This sequence may be stem from the level of cis-oleic which can be arranged in the following order: according to oil type: canola oil $>$ palm oil $>$ sunflower oil.

The amount of trans-linoleic acid in canola oil was very low compared with trans-oleic of other two oils during the various heating periods. This may be due the low level of cis-linoleic acid compared with cis-oleic acid.

In general, the total amounts of trans $\mathrm{C} 18$ fatty acids at the end of this series of experiments can be arranged in the following order: sunflower oil $>$ canola oil $>$ palm oil. These findings are in contrast with the results of the nutritional experiments reported by Farag et al., [13] where the major alteration induced to rat organ tissues (liver, kidney, heart) when rats administered the heated sunflower oil, palm oil and canola oil as part of their diet. The changes on rat organ tissues were related to the type of fatty acids (erucic acid in canola oil and palmitic acid in palm oil). Several reports indicated that trans acids induced deleterious effects on human health [14]. This fact was not found in the present work. This is might be due to the presence of trans-acids in very low amounts (lower than $2 \%$ in sunflower oil and $0.2 \%$ in canola and palm oils). Similar results were reported by Nestel et al. [5].

\subsection{Trans Fatty Acids of Sunflower Oil and Canola Oil Blends}

Table 2 shows the effect of blending different ratios of canola oil with sunflower oil and heated for various periods. Generally speaking, the levels of elaidic increased with increasing the heating period and mixing 


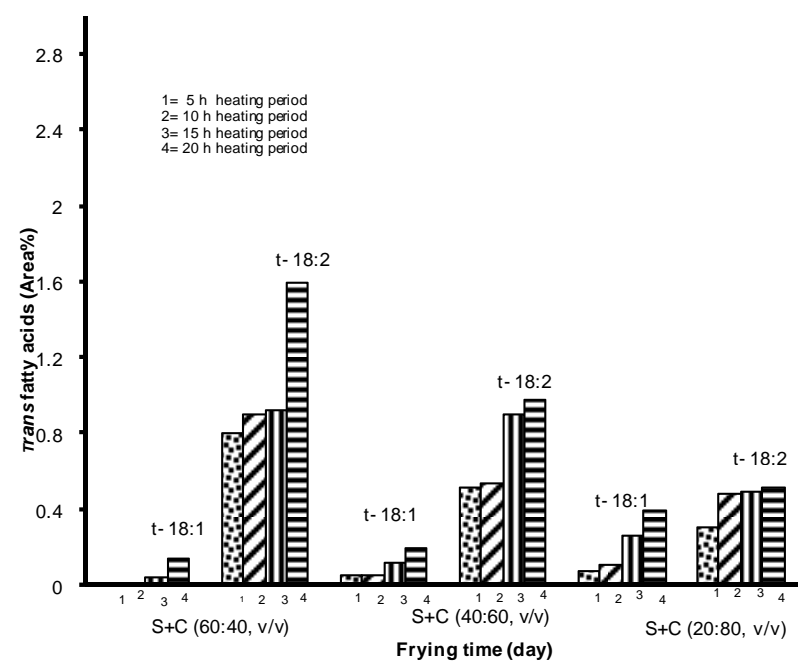

Figure 2. Trans fatty acids of fried sunflower oil (S) mixed with various levels of canola oil (C) heated for different periods. t- 18: 1 and t- 18: 2 indicate trans-oleic and translinoleic acids, respectively

ratios. In the mean time, the level of cis-oleic was slightly increased with heating time. It is noticeable that its amount increased by increasing the blending ratio and in particular at the volume ratio of 20:80 (v/v) (Figure 2).

Here again, the amount of trans-linoleic increased at all volume ratios with prolonging the heating period. On the contrary, its level was progressively decreased with increasing the blending ratios. Concerning cis-linoleic acid, its levels were remarkably decreased with extending the heating period and increasing with increasing the level of canola in the blending ratios. The results with the total trans-oleic and linoleic acids are greed quite well with the previous findings (Table 2, and Figure 2).

\subsection{Trans Fatty Acids of Sunflower Oil and Palm Oil Blends}

The amounts of trans-oleic acid and its parent acid of heated sunflower oil and mixed with heated palm oil at volume ratio of 60: $40(\mathrm{v} / \mathrm{v})$ for various periods are shown in Table 3. In general, the results demonstrate a progresssive increase in the amount of elaidic with prolonging the heating period. The amount of linolaidic acid formation was more pronounced than that of elaidic acid with

Table 2. Trans and their parent fatty acid compositions (area \%) of heated binary mixtures of sunflower oil (S) and canola oil (C) for various periods

\begin{tabular}{|c|c|c|c|c|c|c|c|c|}
\hline \multirow{2}{*}{ Oil blend } & \multicolumn{8}{|c|}{ Heating period (h) } \\
\hline & 5 & 10 & 15 & 20 & 5 & 10 & 15 & 20 \\
\hline & \multicolumn{4}{|c|}{$\underline{\text { Trans-oleic acid (elaidic) acid }}$} & \multicolumn{4}{|c|}{ Cis-oleic acid } \\
\hline$S+C(60: 40, v / v)$ & ND & ND & 0.04 & 0.14 & 33.89 & 34.56 & 34.61 & 33.61 \\
\hline$S+C(40: 60, v / v)$ & 0.05 & 0.05 & 0.12 & 0.20 & 40.74 & 43.07 & 42.59 & 43.57 \\
\hline \multirow[t]{2}{*}{$\mathrm{S}+\mathrm{C}(20: 80, \mathrm{v} / \mathrm{v})$} & 0.07 & 0.11 & 0.26 & 0.40 & 42.19 & 42.50 & 42.49 & 42.47 \\
\hline & \multicolumn{4}{|c|}{ Trans-linoleic (linolaidic) acid } & \multicolumn{4}{|c|}{ Cis-linoleic acid } \\
\hline$S+C(60: 40, v / v)$ & 0.80 & 0.90 & 0.92 & 1.60 & 47.89 & 45.89 & 44.91 & 42.42 \\
\hline$S+C(40: 60, v / v)$ & 0.52 & 0.54 & 0.90 & 0.98 & 34.65 & 32.14 & 31.78 & 29.74 \\
\hline \multirow[t]{2}{*}{$\mathrm{S}+\mathrm{C}(20: 80, \mathrm{v} / \mathrm{v})$} & 0.31 & 0.48 & 0.49 & 0.52 & 27.22 & 27.35 & 26.65 & 24.81 \\
\hline & & Total & acids & & & & & \\
\hline$S+C(60: 40, v / v)$ & 0.80 & 0.90 & 0.96 & 1.74 & & & & \\
\hline$S+C(40: 60, v / v)$ & 0.59 & 0.65 & 1.16 & 1.38 & & & & \\
\hline $\mathrm{S}+\mathrm{C}(20: 80, \mathrm{v} / \mathrm{v})$ & 0.36 & 0.53 & 0.61 & 0.72 & & & & \\
\hline
\end{tabular}

ND refers to non detected fatty acid

Table 3. Trans and their parent fatty acid compositions (area \%) of heated binary mixtures of sunflower oil (S) and palm oil (P) for different periods

\begin{tabular}{|c|c|c|c|c|c|c|c|c|}
\hline \multirow{2}{*}{ Oil blend } & \multicolumn{8}{|c|}{ Heating period (h) } \\
\hline & 5 & 10 & 15 & 20 & 5 & 10 & 15 & 20 \\
\hline & \multicolumn{4}{|c|}{$\underline{\text { Trans-oleic acid (elaidic) acid }}$} & \multicolumn{4}{|c|}{$\underline{\text { Cis-oleic acid }}$} \\
\hline$S+P(60: 40, v / v)$ & 0.03 & 0.04 & 0.09 & 0.13 & 31.80 & 31.48 & 32.40 & 32.98 \\
\hline $\mathrm{S}+\mathrm{P}(40: 60, \mathrm{v} / \mathrm{v})$ & 0.03 & 0.05 & 0.18 & 0.20 & 33.64 & 34.80 & 34.77 & 34.96 \\
\hline \multirow[t]{2}{*}{$\mathrm{S}+\mathrm{P}(20: 80, \mathrm{v} / \mathrm{v})$} & 0.04 & 0.05 & 0.21 & 0.48 & 35.36 & 34.91 & 34.85 & 34.40 \\
\hline & \multicolumn{4}{|c|}{$\underline{\text { Trans-linoleic (linolaidic) acid }}$} & \multicolumn{4}{|c|}{$\underline{\text { Cis-linoleic acid }}$} \\
\hline$S+P(60: 40, v / v)$ & 0.77 & 0.79 & 0.90 & 0.92 & 37.19 & 38.28 & 35.71 & 34.96 \\
\hline$S+P(40: 60, v / v)$ & 0.53 & 0.54 & 0.64 & 0.73 & 28.96 & 26.54 & 23.19 & 17.17 \\
\hline$S+P(20: 80, v / v)$ & 0.33 & 0.33 & 0.36 & 0.40 & 19.19 & 18.77 & 16.14 & 15.38 \\
\hline \multicolumn{9}{|c|}{ Total trans $\mathrm{C} 18$ fatty acids } \\
\hline$S+P(60: 40, v / v)$ & 0.80 & 0.83 & 0.99 & 1.05 & & & & \\
\hline$S+P(40: 60, v / v)$ & 0.56 & 0.61 & 0.82 & 0.93 & & & & \\
\hline $\mathrm{S}+\mathrm{P}(20: 80, \mathrm{v} / \mathrm{v})$ & 0.37 & 0.38 & 0.57 & 0.88 & & & & \\
\hline
\end{tabular}




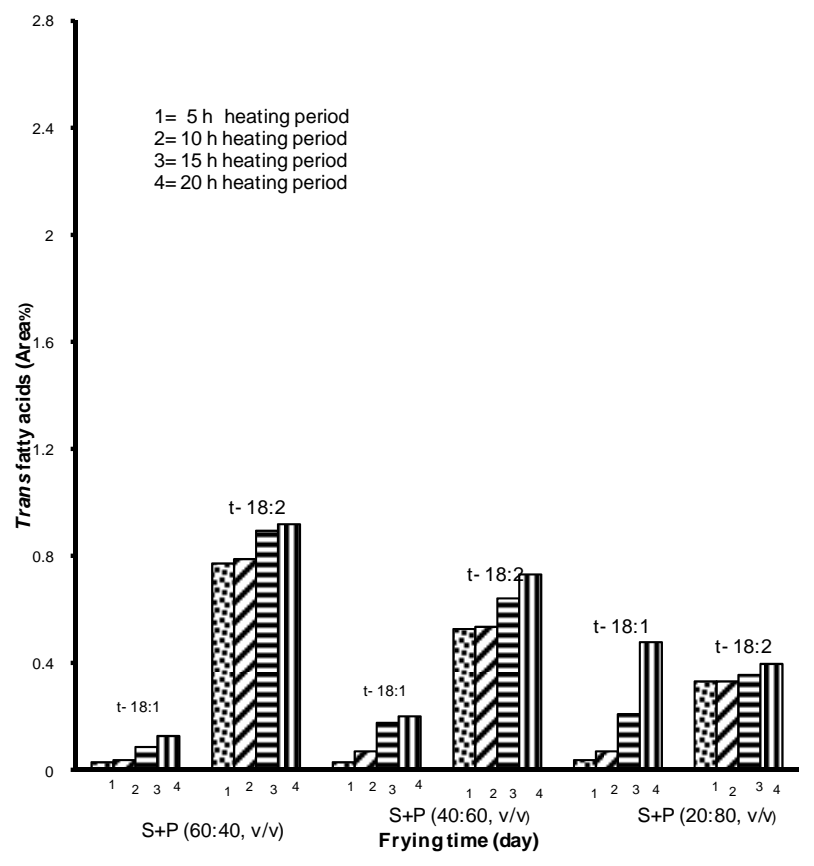

Figure 3. Trans fatty acids of fried sunflower oil (S) mixed with various levels of palm oil $(P)$ heated for different periods. $t-18: 1$ and $t-18: 2$ indicate trans-oleic and translinoleic acids, respectively

increasing the heating time (Figure 3). This might be due to the fact that the amount of cis-linoleic is higher than cis-oleic acid. Also, one has to mention that cis-linoleic acid is much labile than cis-oleic acid and rate of steromutation is in the favour of linoleic acid.

With increasing the mixing ratios of heated palm oil with heated sunflower oil (60: 40 and 20: 80, v/v) led to an increase of the amount of elaidic acid. It is worth mentioning that the levels of cis-oleic acid slightly increased with increasing the ratio of blending palm oil with sunflower oil. On the contrary, the level of linolaidic acid decreased with increasing the admixture ratios of palm oil (Figure 3). This is logic since the amount of cis-18: 2 was decreased with the admixture ratio.

The results in Table 3 indicate that the amount of total trans C18-fatty acids decreased with increasing the volume ratio of palm oil with sunflower oil during frying. Similar findings were seen by the increasing the mixing of canola oil with sunflower oil during frying. These findings led to deduce that mixing sunflower oil with canola or palm oils induced lowering effect on the total-trans fatty acids during frying. In this case one would say mixing sunflower oil with other oils rich in monounsaturated acid might reduce the formation of trans fatty acids during frying which is in the favor of human health.

The ratio of linoleic acid to palmitic acid (C18: 2/C16: 0 ) has been suggested by Normand et al., [15] as a valid indicator of the level of polyunsaturated fatty acid deterioration. The results of the present work showed a de- crease in this ratio from 9.02 to $6.79,3.82$ to 2.93 and 0.24 to 0.22 at the end frying period for sunflower, canola and palm oils respectively. The ratios indicate the incidence of deterioration of polyunsaturated fatty acids of the oils under frying process.

\section{REFERENCES}

[1] G. L. Khor and N. M. Esa, "Trans Fatty Acids Intake: Epidemiology and Health Implications," In A. J. Dijkstra, R. J. Hamilton and W. Hamm, Ed., Trans Fatty Acids, Blackwell Publishing, Oxford, 2008, pp. 25-45.

[2] H. J. Heipieper, F. Meinhardt and A. Segua, "The CisTrans Isomerase of Unsaturated Fatty Acids in Pseudomonas and Vibrio: Biochemistry Molecular Biology and Physiological Function of a Unique Stress Adaptive Mechanism," FEMS Microbiology Letters, Vol. 229, No. 1, 2003, pp. 1-7.

[3] D. Mozaffarian, M. B. Katan, A. Ascherio, M. J. Stampfer and W. C Willett, "Trans Fatty Acids and Cardiovascular Disease," New England Journal of Medicine, Vol. 354, No. 15, 2006, pp. 1601-1613.

[4] P. L. Zock and M. B. Katan, "Hydrogenation Alternatives: Effect of Trans Fatty Acids and Stearic Acid Versus Linoleic on Serum Lipids and Lipoproteins in Humans," Journal of Lipid Research, Vol. 33, No. 3, 1992, pp. 399410.

[5] P. J. Nestel, M. Noakes, G. B. Belling, R. McArthur, P. M. Clifton and M. Abbey, "Plasma Cholesterol Lowering Potential of Edible Oil Blends Suitable for Commercial Use," American Journal of Clinical Nutrition, Vol. 55, No. 1, 1992, pp. 46-50.

[6] K. Warner, "Chemical and Physical Reactions in Oil during Frying,” In: M. K. Gupta, K. Warner and P. J. White, Ed., Frying Technology and Practice, American Oil Chemists' Society, Champaign, 2004, pp. 16-28.

[7] M. Moreno, D. M. Olivares, F. J. A. Lopez, J. V. G. Adelantado and F. B. Reig, "Determining Low Levels of Trans Fatty Acids in Foods Using an Improved ATR-FTIR Procedure," Lipid Technology, Vol. 16, No. 11, 1999, pp. 252- 255.

[8] A. Romero, C. Cuesta and F. J. Sanchez-Muniz, "Trans Fatty Acid Production in Deep-Fat Frying of Frozen Foods with Different Oils and Frying Modalities," Nutrition Research, Vol. 20, No. 4, 2000, pp. 599-608.

[9] J. E. Hunter and T. H. Applewhite, "Reassessment of Trans Fatty Acid Availability in the U.S. Diet," American Journal of Clinical Nutrition, Vol. 54, No. 2, 1991, pp. 363369.

[10] Food and Drug Administration, "FDA Acts to Provide Better Information to Consumers on Trans Fats," 2005. http://www.Fda.gov/oc/initiatives/transfat/

[11] Dietary Guidelines Advisory Committee, "Nutrition and your Health: Dietary Guidelines for Americans," Dietary Guidelines Advisory Committee Report, Department of Agriculture, Washington, D.C., 2005. http://www.Health. 
Gov/dietaryguidlines/dga2005/report/

[12] UK Faculty of Public Health/Royal Society for Public Health, "12 Steps to Better Public Health: A Manifesto." http://www.fphm.org.uk/resources/AtoZ/manifesto/manif esto.pdf

[13] R. S. Farag, M. S. Abdel-Latif, A. M. M. Basuny, B. S. Abd El-Hakeem, "Effects of Non-Fried and Fried Oils with Varying Fatty Acid Compositions on Rat Organs," Advances in Food Sciences, Vol. 32, No. 3, 2010, pp.
128-136.

[14] R. Micha, and D. Mozaffarian, "Trans Fatty Acids: Effects on Cardiometabolic Health and Implications for Policy," Prostaglandins, Leukotrienes and Essential Fatty Acids, Vol. 79, No. 3-5, 2008, pp.147-152.

[15] L. Normand, N. A. M. Eskin and R. Przybylski, "Effects of Tocopherols on the Frying Stability of Regular and Modified Canola Oils," Journal of American Oil Chemists' Society, Vol. 78, No. 4, 2001, pp. 369-373. 